\title{
Panorama geral das Escolas Agrotécnicas Federais após a Reforma da Educação Profissional (1997-2003) ${ }^{1}$
}

\section{General landscape of Agricultural Schools after the Reform of Professional Education (1997-2003)}

\author{
Moacir Gubert Tavares ${ }^{2}$ \\ Flávio Massao Matsumoto ${ }^{3}$
}

\begin{abstract}
RESUMO
Este artigo pretende analisar a situação do ensino técnico brasileiro a partir da Reforma da Educação Profissional (REP) realizada durante o período de vigência do Decreto 2.208/97. Tal análise se embasa no panorama geral das Escolas Agrotécnicas Federais, as quais passaram por mudanças significativas no período de 1997 a 2003. Além da pesquisa bibliográfica e da análise de diversos documentos que nortearam a Reforma, a coleta dos dados considerados neste artigo contou ainda com uma pesquisa de campo que reuniu informações essencialmente qualitativas, por meio de entrevistas pré-estruturadas dirigidas a oito professores que compõem os quadros docentes de duas Escolas Agrotécnicas Federais (EAF) visitadas pelo pesquisador. Os resultados sugerem que professores e alunos tiveram que aderir à Reforma da Educação Profissional (REP) sem que houvesse tempo suficiente para o debate no interior das Escolas. Alterações como a separação entre ensino médio e ensino técnico, a adoção de currículos modulares e o uso de competências profissionais na organização de
\end{abstract}

${ }^{1}$ Esta pesquisa recebeu apoio da Coordenação de Aperfeiçoamento de Pessoal de Nível Superior (CAPES), através da concessão de bolsa ao pesquisador durante a realização do seu mestrado na Universidade Federal do Paraná (UFPR).

${ }^{2}$ Mestre em Educação pela UFPR. Docente do Instituto Federal Catarinense - Campus Rio do Sul. Doutorando do Programa de Pós-Graduação em Educação da Universidade Estadual de Ponta Grossa (UEPG), Brasil.

${ }^{3}$ Professor Doutor do Departamento de Química da UFPR e orientador da pesquisa de mestrado. 
conteúdos trouxeram impactos negativos para as EAF, que vão desde a fragmentação da formação profissional até a redução da carga horária destinada às aulas práticas dos alunos. De fato, as mudanças promovidas pela Reforma foram suficientes para desmontar toda uma organização que historicamente vinha conferindo à rede de Escolas Agrotécnicas Federais o status de centros de excelência neste ramo de ensino profissionalizante.

Palavras-chave: ensino técnico; ensino médio; Reforma da Educação Profissional.

\begin{abstract}
This research aims to examine the situation of Brazilian technical teaching after the Reform of Professional Education (REP) happened during the period of the validity of Decree number 2,208/97. The base of this analyze is the general background of Agricultural Schools which went through intense changes in the period of 1997 to 2003. Besides literature research and the analyze of various documents that guided the Reform, some data used in this article came from an empirical investigation. It brought essentially qualitative information, in which eight teachers from two different Federal Agricultural Schools visited by the researcher responded a preoriented questionaire. The responses suggest that both, teachers and pupils had to adhere the Reform of Professional Education without an appropriate debate inside the schools. Changes such as the separation between high school and technical education, the adoption of curriculum under the form of professionalizing modules and the use of professional skills in the organization of subjects brought negative impacts to the agricultural schools, such as the fragmentation of the professional formation or the reduction of quantity of hours of practical classes. Actually the changes the Reform caused were sufficient to dismount a whole organization that historically had been given the federal agricultural schools network the status of excellency centers in professional teaching.
\end{abstract}

Keywords: technical teaching; high school; Reform of Professional Education.

\title{
Introdução
}

Este trabalho se propõe a ampliar a compreensão sobre o processo de Reforma da Educação Profissional (REP), implementada no Brasil a partir da 
Lei de Diretrizes e Bases da Educação Nacional (LDB) nº 9.394/96 e do Decreto Presidencial 2.208/974.

As modificações de maior relevância para o ensino profissional de nível técnico, resultantes da REP, podem ser resumidas da seguinte maneira:

a) separação entre formação geral (ensino propedêutico) e formação técnica (ensino profissionalizante) através de matrículas e currículos distintos para seus alunos, de modo que a educação técnica passa a fazer parte do ensino não regular;

b) estruturação curricular dos cursos sob a forma de módulos profissionalizantes, o que dá aos seus concluintes a possibilidade de receber um Certificado de Qualificação Profissional, para os módulos com terminalidade;

c) substituição do conceito de qualificação pela noção de competências (centrada nos atributos individuais do trabalhador) nas escolas de ensino profissionalizante.

A separação entre a formação geral e formação específica dos cursos técnicos possibilitou o surgimento de três diferentes modalidades de ensino técnico: concomitância interna, concomitância externa e sequencial ${ }^{5}$ (pós-médio). Nas concomitâncias interna e externa, apesar de os alunos frequentarem o ensino técnico e o ensino médio concomitantemente, as matrículas e matrizes curriculares organizam-se separadamente em cada um destes níveis. No caso da concomitância interna, enquadram-se os alunos que possuem matrículas para o ensino técnico e para o ensino médio em uma mesma instituição de ensino, enquanto na concomitância externa, aqueles que possuem matrículas em instituições distintas. Na modalidade pós-médio, o princípio da sequencialidade permite aos alunos que já tiverem concluído previamente o nível médio o direito de cursar apenas a parte profissionalizante para a obtenção do Diploma de Técnico, ou seja, sua formação geral se dá em um momento distinto daquele em que ocorre a formação específica.

Além de divorciar a formação geral e a formação específica, por meio desta Reforma fragmenta-se o conjunto de disciplinas que antes constituía a parte profissionalizante dos antigos currículos da Agropecuária, com a criação de diversas habilitações profissionais de cunho mais específico. A formação de

${ }^{4}$ Durante a primeira gestão do Presidente Luiz Inácio Lula da Silva (2003-2006), o Decreto $\mathrm{n}^{\circ} 2.208 / 97$ foi revogado e substituído pelo Decreto ${ }^{\circ} 5.154 / 04$.

${ }^{5}$ A modalidade sequencial, também conhecida como pós-médio, passou a denominar-se subsequente a partir do surgimento do Decreto 5.154/04. 
Técnico Agrícola, a partir de então, ocorre através de habilitações diversas, como Agricultura, Zootecnia, Agroindústria, entre outras, tendendo à especialização deste profissional. A carga horária mínima de cada curso, independentemente da habilitação profissional, passa a ser de 1.200 horas, já incluídas as aulas práticas, mas desconsiderando-se a carga horária do estágio curricular supervisionado.

O modelo das competências, também introduzido pela Reforma da Educação Profissional (REP), substitui as antigas formas de planejamento e avaliação escolar. No processo de adequação das escolas técnicas brasileiras às novas diretrizes do Ministério da Educação e Cultura (MEC), o conceito de competência profissional ganhou papel de destaque nas discussões travadas entre os profissionais da educação. Todavia, o seu caráter polissêmico e a falta de clareza quanto ao seu significado resultaram em compreensões inadequadas e insuficientes sobre este conceito. Para DELUIZ (2003), a utilização de distintos modelos epistemológicos pelos documentos da REP demonstra uma confusão conceitual entre competências e habilidades, por exemplo.

Diante de tais considerações, este trabalho tem como objetivos, de maneira mais ampla, verificar:

a) os impactos da REP no ensino técnico agrícola, considerando-se as particularidades das escolas agrotécnicas (principalmente no que se refere ao modelo Escola-Fazenda) e as especificidades dos alunos atendidos por estas;

b) os diferentes caminhos trilhados pelas escolas agrotécnicas no processo de autoadequação às inovações implementadas pela REP.

A concepção de educação profissional que se privilegia neste trabalho se baseia nos textos de Antônio Gramsci, tendo-o como referência central para a discussão efetuada em torno da relação entre educação e trabalho. Gramsci defende um modelo de escola unitária, politécnica, que toma o trabalho como princípio educativo, em oposição à divisão dos sistemas escolares e à oferta de tipos distintos de educação. Esta concepção de educação à qual se refere o autor se caracteriza também por objetivar o desenvolvimento integral do homem, ou seja, a sua omnilateralidade. Do ponto de vista de Gramsci (1978, p. 136):

Não é a aquisição de capacidades diretivas, não é a tendência a formar homens superiores que dá a marca social de um tipo de escola. A marca social é dada pelo fato de que cada grupo social tem um tipo de escola próprio, destinado a perpetuar nesses grupos uma determinada função tradicional, diretiva ou instrumental. Se se quer destruir essa trama, portanto, deve-se evitar a multiplicação e graduação dos tipos de escola 
profissional, criando-se, ao contrário, um tipo único de escola preparatória (elementar-média) que conduza o jovem até os umbrais da escolha profissional, formando-o entrementes como pessoa capaz de pensar, de estudar, de dirigir ou de controlar quem dirige.

No que tange ao ensino técnico agrícola, entende-se que a formação profissional dos intelectuais que irão atuar direta ou indiretamente no setor produtivo deve levar em conta não apenas os avanços tecnológicos e os paradigmas que se apresentam na atualidade, mas também as especificidades do cenário rural brasileiro, as condições concretas de produção que constituem a realidade da maioria dos trabalhadores rurais do país e as necessidades dos indivíduos que procuram por este ensino. Para tanto, não basta um ensino agrícola que atenda aos interesses do mercado de trabalho. É necessário outro tipo de ensino, que contemple também as dimensões política, cultural, humanística, enfim, a formação integral do sujeito, que deve ocorrer independentemente da função que este irá desempenhar na sociedade.

\section{Metodologia}

Os dados apresentados neste artigo foram coletados no ano de 2003 e resultaram na dissertação de mestrado que tem como título Formação de trabalhadores para o meio rural: os impactos da Reforma da Educação Profissional no ensino técnico agrícola. Além da pesquisa bibliográfica e da análise documental, a coleta dos dados considerados neste artigo contou ainda com uma pesquisa de campo que reuniu dados essencialmente qualitativos, através de entrevistas pré-estruturadas dirigidas a oito professores que compõem os quadros docentes de duas Escolas Agrotécnicas Federais (EAF) visitadas pelo pesquisador: a Escola Agrotécnica Federal de Sombrio-SC e a Escola Agrotécnica Federal de São Vicente do Sul-RS ${ }^{6}$. Cabe ressaltar que, apesar de ter sido transformada em CEFET em outubro de 2002, os cursos ofertados por esta última instituição estão sujeitos às mesmas exigências legais válidas para a rede de EAF. Por essa razão, a transformação em CEFET não afetou o resultado desta pesquisa.

${ }^{6}$ No texto desse artigo, a denominação "escola agrotécnica" compreende também os CEFET e UNED que originalmente faziam parte da rede de EAF. 
As questões utilizadas nas entrevistas pré-estruturadas buscaram caracterizar as mudanças ocorridas no interior das Escolas, tanto aquelas relacionadas à sua organização pedagógica quanto aquelas relacionadas ao sistema de funcionamento do modelo Escola-Fazenda. Depois de gravadas em fitas cassete, as entrevistas foram transcritas pelo pesquisador e posteriormente o seu conteúdo foi confrontado com o discurso presente nos documentos oficiais que nortearam a Reforma da Educação Profissional e com a produção científica existente acerca deste tema específico.

\section{Resultados e discussões}

As observações realizadas in loco indicam que as diferentes EAF investigadas apresentavam características e materialidades que lhes são peculiares, decorrentes do meio e das circunstâncias em que estão inseridas. Consequentemente, os rumos e direções tomados por cada uma destas instituições na tentativa de se adequarem à REP também se mostraram variados.

Depois de construído todo o arcabouço legal que sustentou essa Reforma, no plano concreto a sua implantação coube a outros sujeitos, que não são aqueles mesmos que participaram da sua elaboração enquanto projeto de educação. A reformulação do ensino técnico agrícola, na prática, foi feita por professores, funcionários, alunos e dirigentes das escolas agrotécnicas.

A implementação da REP contou com o apoio do Programa de Expansão da Educação Profissional (PROEP), que também iniciou em 1997 e se desenvolveu paralelamente aos propósitos do Decreto 2.208/97. Segundo LIMA FILHO (2003, p. 21), o PROEP $^{7}$ promoveu um investimento de recursos da ordem de 500 milhões de dólares para o período 1997-2003. Estas verbas foram utilizadas predominantemente na construção de prédios e benfeitorias. Devido ao fato de a distribuição destes recursos estar condicionada à adesão das diversas instituições de ensino profissional à REP, este Programa se constituiu no principal instrumento de implantação da reforma.

A realização de matrículas separadas para os níveis técnico e médio a partir de 1998, que se tornou obrigatória com a edição do Decreto 2.208/97, foi a primeira adequação tomada pelas EAF. De encontro a esta medida, a redução

\footnotetext{
${ }^{7}$ Os recursos utilizados pelo PROEP são oriundos do orçamento da União (MEC), do Fundo de Amparo ao Trabalhador (FAT) e de empréstimo internacional junto ao Banco Interamericano de Desenvolvimento (BID), que é o principal financiador externo da reforma.
} 
gradativa da oferta do ensino médio pela rede federal fazia parte dos planos do MEC, conforme o estabelecido pela Portaria 646/97.

Ainda que isso não estivesse explícito nos documentos da REP, a transferência da responsabilidade pela oferta e financiamento do ensino médio para as demais esferas da rede pública e privada, bem como a consequente desobrigação por parte da União (que assumiria, além do superior, apenas a manutenção do ensino técnico e tecnológico), também estava entre as suas prioridades. Para Lima Filho (2003, p. 37), a velocidade com que as instituições federais de educação profissional extinguissem o ensino médio era critério para a obtenção de recursos. A sua concretização, contudo, esbarrou na forte resistência dos professores, embora isso não tenha acontecido em todas as Escolas.

Embora a extinção completa do ensino médio não tenha sido observada na maioria das escolas, vale ressaltar que esta era uma orientação geral, válida para todas as EAF. A reportagem feita na EAF de Barbacena-MG, tida como uma das mais antigas do país, divulgada em dezembro de 2001, confirma a intenção de se extinguir a formação propedêutica de nível médio nestas escolas:

Não vamos mais formar técnicos "em agropecuária”. Teremos diferentes habilitações: técnico em agricultura, zootecnia, agroindústria, floricultura ou paisagismo, diz César Romano Quintão, diretor de ensino. A explicação é que estão pensando no futuro dos alunos quando saírem da escola, pois a formação muito genérica não tem potencial empregador no mercado. Por enquanto, a escola continua oferecendo ensino médio, em carga horária separada, mas a previsão é que dentro de cinco anos só esteja trabalhando com cursos profissionalizantes, para quem chegar com o segundo grau concluído (SILVA, 2001, p. 38).

Observe-se que a justificativa para a fragmentação do técnico em agropecuária e a consequente especialização dos profissionais formados por este curso através de diversas habilitações profissionais é a "falta de potencial empregador no mercado" apresentada pelo antigo curso, considerado muito "genérico". Contraditoriamente, o discurso oficial utilizado pelo MEC (principalmente no Parecer CEB/CNE n ${ }^{\circ} 16 / 99$ ) alerta para a necessidade de uma formação profissional dotada de sólida formação geral, que permita ao novo trabalhador transitar entre diferentes postos de trabalho de uma mesma área profissional. Portanto, se no discurso se fala em flexibilidade (e esta pressupõe uma ampla base de formação geral), na prática se implementa fragmentação e especialização dos currículos profissionalizantes. 
A análise do discurso observado nesta narrativa revela, primeiro, o alinhamento dos dirigentes desta escola às exigências do PROEP e, em segundo lugar, o seu atrelamento único aos interesses do mercado de trabalho. Entretanto, nesta mesma reportagem, evidencia-se a polêmica que surge entre alunos e professores em razão da separação entre formação geral e específica. Uma parte destes entende que as instituições responsáveis pela oferta de ensino médio em separado do técnico podem destinar uma maior carga horária para a formação propedêutica, o que, do seu ponto de vista, beneficiaria os alunos que se interessam pelo vestibular. Outros, porém, veem esta mudança como algo negativo e manifestam muita preocupação com os impactos dessa transformação no caso das escolas agrotécnicas:

[...] tanto alunos como professores questionam a opção das escolas agrícolas pelo curso pós-secundário, porque temem que isso possa afastar muitos jovens do meio rural que têm nas escolas agrotécnicas, verdadeiras fazendas equipadas com alojamento e restaurante, o único meio de seguir os estudos depois da oitava série. Caso tenham que cursar o ensino médio em escolas comuns, muitos não poderão deixar o sítio para estudar na cidade. Além disso, concluir o profissionalizante somente depois do segundo grau completo pode ser um caminho longo demais para quem precisa começar a trabalhar cedo (SILVA, 2001, p. 38).

Esta preocupação com a difícil realidade dos alunos de origem rural foi um argumento bastante utilizado por aquelas EAF que insistiram na oferta de ensino médio, contrariamente à orientação do MEC.

Com consequências tão profundas quanto a separação entre o Técnico e o Médio, o currículo modular e a pedagogia das competências passaram a ser adotados pela rede federal mais intensamente a partir de 2001. Foram estas duas medidas as que exigiram mais envolvimento e empenho de dirigentes, professores, funcionários e alunos das escolas agrotécnicas. Ano após ano, novas mudanças foram realizadas em termos de organização dos cursos e de procedimentos metodológicos, buscando-se, por meio de experiências e tentativas, alguma estabilidade para os cursos da Área Agropecuária.

A elaboração do Decreto $n^{\circ} 2.208 / 97$, bem como a sua implementação nas escolas técnicas através do PROEP, ignorou todo o conhecimento acumulado durante anos por professores, pesquisadores, sindicatos, entre outros segmentos organizados da sociedade civil, em torno de um projeto de educação que contemplasse a participação democrática e os interesses da ampla maioria da 
população. Os resultados obtidos pelas entrevistas revelam a insatisfação dos professores através das frequentes afirmações de que a Reforma da Educação Profissional veio como um "pacote" ou que esta foi "imposta" pelo Ministério da Educação (MEC) "de cima para baixo", fato que fortaleceu a contrariedade dos professores em aderir à REP.

O ideal seria que, a partir do momento em que a escola vai fazer uma mudança nestes moldes, de grandes proporções como era essa, quase que radical, em que se tinha um trabalho tradicional e de repente você rompe com tudo isso, [...] [mudando] a tua visão de avaliação, de acompanhamento até mesmo da carga horária dos professores, [...] [ocorresse] um acompanhamento mais de perto, muito mais amplo [...] pelo menos no período em que eu estou aqui [na Coordenação Geral de Ensino], a SEMTEC resolveu fazer essa mudança na educação profissional, mas pelo menos os nossos docentes nunca foram chamados [para discutir a implantação da REP e orientar os professores], e nem mesmo alguém da SEMTEC disse "nós vamos aí na escola repassar esse tipo de informação", [para explicar] como isso deve ser trabalhado [...] eu, pelo menos, nunca participei de nenhum encontro, nenhum curso [...] eu acho que [...] [a solução para] isso também não seria [através de] um curso ou um encontro, mas [por meio de] um período longo de aperfeiçoamento de trabalho, de discussões para que haja essa informação [Professor 1, escola 2].

O estabelecimento de prazos para a implantação das novas diretrizes educacionais levou muitas escolas e professores a aderirem a esse processo de forma mecânica e acrítica. A sobrecarga de trabalho sobre os professores, funcionários e dirigentes destas escolas, além dos problemas oriundos do processo de adequação da Escola-Fazenda ao processo de Reforma, preencheram o tempo disponível destes sujeitos de tal forma que não houve, na maioria dos casos, espaço para a realização de discussões e debates. Depois de se ter questionado um dos professores sobre a forma como se deram as discussões em torno da pedagogia das competências e outras inovações trazidas pela REP, a resposta obtida foi a seguinte:

As coisas mudam e têm que ser implantadas imediatamente. Não tem tempo para essas coisas. Como diz o ditado: "é com o andar da carroça que as abóboras vão se acomodando", e isso foi o que aconteceu. A gente fez algumas reuniões, discutimos algumas coisas, mas as coisas aconteceram mais na execução mesmo [Professor 7 da escola 1]. 
Embora se tenha constatado o caso de um professor que afirmou não ter nenhuma dificuldade quanto ao entendimento do que é a pedagogia das competências, as declarações da maioria dos entrevistados evidenciam que esta questão é encarada por eles como um dos principais entraves ao processo de aplicação das novas diretrizes educacionais:

Entender o que é avaliação por competência e aplicar na íntegra esse tipo de avaliação, até hoje a gente não conseguiu, e se [algum professor em] alguma escola disser que está conseguindo [fazê-lo] plenamente, [...] não deve estar falando a verdade. Porque para começar, é muito difícil porque, para eu dizer que um aluno é competente, que ele atingiu todas as competências, eu tenho que conhecer os alunos um a um. E se o professor tem muitos alunos ele não conhece todos [...]. Se ele tem pouca carga horária semanal (para ficar próximo dos alunos) ele não chega a conhecer os alunos [suficientemente] para dizer "o fulano é apto ou o fulano não é apto". Então essa é uma das [...] grandes dificuldades da Reforma. É um sistema meio utópico [Professor 5, escola 1].

A pesquisa realizada por Soares (2003), que utilizou contatos feitos com dirigentes e docentes de Escolas Agrícolas, sejam elas da rede de EAF ou vinculadas às Universidades, sugere que esta dificuldade acerca da compreensão do conceito de competências, por exemplo, ocorre de forma generalizada entre estas instituições de ensino. Segundo a autora, tal conceito possui um caráter polissêmico e não se apresenta de forma clara nos documentos da política educacional:

[...] quase três anos após a publicação das Diretrizes, ainda são grandes as dúvidas com relação às competências, sobretudo no que se refere à sua avaliação. As matrizes curriculares foram produzidas para atender às exigências do PROEP, mas, em muitos casos, se limitaram a cumprir o fixado pelas Diretrizes e pelos Referenciais Curriculares. (SOARES, 2003, p. 154).

À categoria competência tem sido atribuído um caráter ideológico, tal como concebido no regime de acumulação flexível e incorporado pelas políticas educacionais do Estado. Este novo conceito, pelo poder de sedução que possui ou simplesmente por conveniência, tem sido difundido por intelectuais que historicamente vinham atuando no campo do trabalho, 
[...] com o que o professor vai ficando sem referências para participar do debate e para refletir sobre suas práticas. Criar este emaranhado de concepções pouco claras e lacunares, de modo a não explicitar o real movimento entre educação, trabalho e capital, é uma das finalidades da ideologia. (KUENZER, 2003, p. 6).

Tais dificuldades têm levado alguns professores a disfarçar o uso de antigos procedimentos de ensino e de avaliação escolar, através de adequações apenas teóricas: nestes casos, as adaptações se restringem à substituição de determinados termos e conceitos durante o planejamento escolar, de modo que alguns dos procedimentos utilizados durante as aulas e avaliações, por exemplo, permanecem inalterados.

\begin{abstract}
A escola procurou desde o começo, quando surgiu essa legislação e esse Decreto [2.208/97], [...] ficou realmente firmado e os prazos [para a implantação da Reforma] aconteceram [...] a gente procurou cumprir à risca isso daí, a transformação para o sistema modular, avaliação por competências, desenvolvimento por competência. Mas o que a gente vê aqui é que nós estamos [nos adequando] só no papel. A questão de modularização está bem esquematizada nos planos de ensino, as competências gerais e específicas de cada módulo, elas estão bem inseridas no papel, mas o problema é que os professores não sabem como trabalhar isso [Professor 3, escola 2]
\end{abstract}

As modificações implementadas nas escolas agrotécnicas e nos cursos por elas ofertados também afetaram sensivelmente a formação prática de seus alunos, conforme já foi mencionado. De um modo geral, pode-se observar que, após a Reforma da Educação Profissional, houve uma significativa redução no número de horas de aulas práticas nas disciplinas técnicas, se comparadas ao número de horas dedicadas às aulas práticas no período anterior a esta. Por se tratar de uma escola técnica, a carga horária destinada às atividades práticas é insuficiente, segundo os professores.

O mais difícil para os professores aceitarem foi essa falta de tempo, essa redução das aulas práticas dos alunos, em função de tudo que nós já comentamos aí, do desmembramento de disciplinas etc. Foi um ponto que os professores custaram a aceitar. Até porque já estavam acostumados 
com um outro sistema com mais tempo com os alunos nos setores, e isso foi bastante difícil. [...] Os alunos hoje permanecem menos tempo em atividade prática do que no sistema antigo. E isso no nosso modo de entender dificulta um pouco a aprendizagem técnica do aluno na parte das práticas que eles executam nos setores [UEP's]. Eles têm pouco tempo, e a troca, a rotatividade dos alunos nos setores é muito grande. Então dificulta um pouco neste sentido. $\mathrm{O}$ acompanhamento das práticas realizadas nos setores se tornou um pouco mais difícil, porque o professor não tem tempo para acompanhar todas as turmas. Devido à grande carga horária que tem em sala de aula [Professor 7, escola 1].

Deve-se ressaltar ainda que a compreensão que se privilegia aqui, sobre as dimensões prática e teórica presentes na formação do Técnico, aponta para o conceito de práxis, que articula conhecimento teórico e capacidade de atuar. Para VAZQUEZ (1968, p. 233), “é uma prova de mecanicismo dividir abstratamente em duas partes e depois tentar encontrar uma relação direta e imediata entre um segmento teórico e um segmento prático". O mesmo trabalho que atua como agente humanizador do homem pode negá-lo enquanto tal, na medida em que o pensar e o agir são separados.

Embora anunciado pelas novas diretrizes curriculares, o princípio da flexibilidade curricular, na prática, não foi observado nas escolas investigadas. A obrigatoriedade do desenvolvimento das competências gerais da Agropecuária pelos currículos, conforme determinam os Referenciais Curriculares Nacionais para a Educação Profissional de Nível Técnico, bem como a falta de professores nas EAF, são fatores que limitam a flexibilização dos cursos e currículos. Embora tenham sido registrados alguns relatos de tentativas neste sentido, verificou-se que os resultados não foram satisfatórios.

Nós continuamos com a mesma quantidade de pessoal ou até menos do que tinha antes [da REP]. Muitos módulos são oferecidos ou deixam de ser oferecidos em função da disponibilidade [ou da indisponibilidade] do quadro docente. [...] Por exemplo, agora, na primeira série [que é quando os professores estão disponíveis], a gente acabou oferecendo [a disciplina de] Irrigação porque a gente sabe que no próximo semestre os professores de Agricultura vão estar com a carga horária extrapolada. Então o professor de Irrigação deu aula [durante] um mês para os alunos e [nos] disse: "não têm condições, faltam muitos pré-requisitos [aos alunos]. Nós vamos ter que parar a disciplina de Irrigação e deixar mesmo para [oferecê-la] o ano que vem". Então foi uma tentativa que a gente fez, [a gente] forçou, porque a gente sabe que no próximo semestre estes professores vão estar sobrecarregados. [Professor 5, escola 1]. 
Até mesmo a questão do planejamento e da administração escolar, segundo os professores, tornou-se mais difícil. Muitas situações imprevistas passaram a fazer parte do cotidiano escolar, exigindo um maior envolvimento por parte dos profissionais que atuam nestas instituições.

Outra questão é o impacto na secretaria, da organização na secretaria, as matrículas e transferências, o recebimento de alunos, transferência de alunos, aproveitamento de estudos. Começaram a aparecer várias situações que aqui [na escola agrotécnica] não existiam. [...] o nosso regulamento parece que não serve para nada, porque todos os dias surgem situações novas em que a gente tem que reunir comissões [de professores] para decidir aquelas situações novas que apareceram, porque sempre tem uma situação nova. Isso é um ponto positivo por um lado, porque dá uma mobilidade, a estrutura escolar não fica fechada, aquela coisa estabelecida: 'isto pode e isto não pode'. Mas por outro lado é [responsável por] uma instabilidade, [já] que a gente fica muito preso na burocracia e não avança no lado pedagógico [Professor 5, escola 1].

Resumidamente, o que se observa através das leis e documentos que orientam a REP nas EAF é a elaboração de uma reforma ideal, descolada da realidade, devido à falta de conhecimento por parte daqueles teóricos que participaram mais diretamente deste processo sobre o ensino técnico agrícola. O não oferecimento das condições mínimas necessárias à aplicação das novas diretrizes formuladas pelo MEC, conforme foi constatado, tende a afastar ainda mais a Reforma enquanto proposta de educação da Reforma concreta, que ocorreu nas escolas investigadas.

\section{Considerações finais}

A Reforma da Educação Profissional foi responsável por impactos profundos na política e na organização dos cursos técnicos e das instituições especializadas na sua oferta. No caso do ensino agrícola, considerando-se as especificidades dos cursos, do público atendido e das escolas onde este ocorre, os dados indicam um quadro de instabilidade que, se não ocasionou prejuízos, muito pouco contribuiu para e elevação da sua qualidade. 
Apesar de apoiar-se num discurso voltado para o atendimento às novas demandas do mundo do trabalho (globalizado), a REP aconteceu muito mais pelo interesse do Governo brasileiro em buscar alternativas de financiamento para a educação do país, subjugando-se às exigências dos organismos financeiros internacionais. Os recursos do PROEP e sua restrição àqueles que se recusaram a aderir à Reforma se constituíram como principal forma de "convencimento" dos gestores da rede federal de ensino técnico.

A separação entre o ensino técnico e o ensino médio, numa perspectiva de educação integradora, segue na contramão de qualquer proposta pedagógica fundamentada no estabelecimento de uma relação íntima entre teoria e prática ou, ainda, na intercomplementaridade entre conhecimento geral e específico. Já os módulos curriculares e as competências, talvez pelo fato de terem sido abordados de forma tão superficial, nem de perto conseguiram atingir os objetivos a que se propunham, qual seja avançar rumo a uma concepção de organização curricular mais flexível e de avaliação mais qualitativa e globalizante, respectivamente.

De fato, as mudanças promovidas pela Reforma foram suficientes para desmontar toda uma organização que historicamente vinha conferindo à rede de Escolas Agrotécnicas Federais o status de centros de excelência neste ramo de ensino profissionalizante. A este novo cenário esteve associada uma política de forte cunho neoliberal, antidemocrática, baseada num modelo de Estado Mínimo, o que agravou ainda mais a insatisfação dos sujeitos que foram envolvidos na sua implantação.

A resposta destas Instituições, que clamavam pela revogação do Decreto 2.208/97 e vários outros atos normativos desencadeados a partir deste, ganhou ressonância com a eleição de um novo Presidente da República em 2002, que, juntamente com sua equipe de governo, substituiu-o pelo Decreto 5.154/04. Este novo documento, sem pretender promover alterações tão radicais quanto aquelas observadas no período de 1997-2003, assegurou a possibilidade de manutenção do que se encontrava vigente, restabelecendo a possibilidade de retorno gradativo ao que existia antes da REP. 


\section{REFERÊNCIAS}

BRASIL. Ministério de Educação e Cultura. Lei nº 9.394. Brasília, dezembro, 1996. . Ministério de Educação e Cultura. Decreto 2.208. Brasília, abril, 1997a. . Ministério de Educação e Cultura. Portaria 646. Brasília, maio, 1997 b. . Conselho Nacional de Educação. Câmara de Educação Básica. Parecer 16/99. Brasília, outubro, 1999. - Ministério de Educação e Cultura. Referenciais curriculares nacionais da educação profissional de nível técnico: área agropecuária. Brasília, 2000. . Ministério de Educação e Cultura. Decreto 5.154. Brasília, julho, 2004.

DELUIZ, N. O modelo das competências profissionais no mundo do trabalho e na educação: implicações para o currículo. Disponível em: $<$ http://www.senac. br/informativo/ BTS /273/boltec273b.htm> Acesso em: 07 out. 2003.

GRAMSCI, A. Os intelectuais e a organização da cultura. Rio de Janeiro: Civilização Brasileira, 1978.

KUENZER, A. Z. Conhecimento e competências no trabalho e na escola. Disponível em: $<$ http://www.senac.br/informativo/BTS/282/boltec282a.htm> Acesso: em 07 jul. 2003.

LIMA FILHO, D. L. A desescolarização da escola: impactos da reforma da educação profissional (período 1995-2002). Curitiba: Torre de Papel, 2003. 124 p.

SILVA, G. A difícil prova de conjugar o futuro: mudanças nos cursos profissionalizantes provocam debate sobre as escolas agrotécnicas em todo o país e o lugar dos técnicos agrícolas no disputado mercado de trabalho. Globo Rural, p. 36-42, dez. 2001.

SOARES, M. D. Política educacional e configurações dos currículos de formação de técnicos em agropecuária, nos anos 90: regulação ou emancipação? Rio de Janeiro, 2003. Tese (Doutorado em Desenvolvimento, Agricultura e Sociedade) - Universidade Federal Rural do Rio de Janeiro.

VAZQUEZ, A. S. Filosofia da práxis. Rio de Janeiro: Paz e Terra, 1968.

Texto recebido em 11 de maio de 2010.

Texto aprovado em 02 de setembro de 2010. 